\title{
Women's Knowledge and Opinions Regarding Emergency Contraception
}

\author{
Krishna Dahiya, Sonika Mann, Smiti Nanda
}

\begin{abstract}
Aim: To know the knowledge and use of contraceptive methods, especially awareness of emergency contraception among women attending gynecology OPD at PGIMS, Rohtak.

Study design: Cross-sectional, questionnaire-based study.

Materials and methods: The study was carried out among patients and their attenders attending postpartum center at PGIMS outpatient department, Rohtak. Both married and unmarried women in the reproductive age group were enrolled. A questionnaire was given concerning questions on knowledge and use of contraceptive methods and awareness of emergency contraception.
\end{abstract}

Results: Out of 500 women, 450 women consented for the study. The subjects were both literate $(65.1 \%)$ and illiterate $(34.9 \%)$, and belonged to an urban (33.2\%) and rural (66.8\%) background. Of the 419 married women, $92 \%$ practiced contraception, among them $70 \%$ were regular users. 110 respondents underwent abortions of which 26 had spontaneous and 84 had induced abortions. Among the available contraceptive methods, condom was the most popular method in 171 women (38\%) followed by Copper-T in 50 women (11.1\%). The use of hormonal contraception was very low $9 \%$. P rint and electronic media were the common source of public awareness in 149 subjects $(57.7 \%), 55$ women (12.2\%) were aware and only six women used emergency contraception.

Conclusion: The awareness of emergency contraception was low in both literate and in illiterate population. With rural background the awareness about emergency contraception was almost nil, about proper timing, use and its side effects. Appropriate awareness programs on EC are needed for the population, so that they can benefit maximum from it.

Keywords: E mergency contraception, Knowledge; A wareness.

How to cite this article: Dahiya K, Mann S, Nanda S. Women's Knowledge and Opinions Regarding Emergency Contraception. J South Asian Feder Obst Gynae 2012;4(3):151-154.

Source of support: Nil

Conflict of interest: None declared

\section{INTRODUCTION}

Emergency contraception is an important backup measure for any breach in regular contraceptive use. ${ }^{1-3} \mathrm{Also}$ useful after unprotected sexual intercourse, contraceptive failure and victims of sexual assault. Taken timely, it could potentially avert many of the millions of unintended pregnancies. ${ }^{4}$ The various options for postcoital contraception are: Emergency contraceptive pills (ECP), combination pill (estrogen and progesterone) or progestin-only oral contraceptives-danazol, Y uzpe regimen (ethinyl estradiol $50 \mu \mathrm{g}$ and levonorgestrel $0.5 \mathrm{mg}$ ), mifepristone, centchroman, anti-estrogens, antiprogestogens and progestogens, or insertion of IUD. ${ }^{5}$ The department of Family W elfare, M inistry of Health and Family
W elfare, has introduced emergency contraceptive pills in the Family W elfare Program, as a contribution to achieving the National Population Policy goals. ${ }^{6}$ Emergency contraceptive pills (ECP) are also known as 'the morning after pill', 'interception', 'postcoital contraception' or 'vacation pill'. It consists of high doses of the same hormones used in oral contraceptive pills. ${ }^{4}$ The ECP are effective only if used within 72 to 120 hours of unprotected sex. ${ }^{5}$ The hormonal emergency contraception concept was introduced in India in 2000. N ow even government supply of ECP is available. In 2003, emergency contraception pill was introduced in heal th centers and hospitals by the name of EC pill in India. It has levonorgestrel (0.75). Two pills are to be taken first within 72 to 120 hours of unprotected sexual intercourse; and another, after 12 hours of taking the first pill. Current recommendation states that two pills can be taken together also. EC pill is considered superior over the previous $Y$ uzpe method because of its having more advantages and minimal side effects. ${ }^{7}$ Lot of western studies ${ }^{8,9}$ are available on emergency contraception, however, the impact of media on contraceptive awareness is not visible in India and rural population across the globe.

\section{MATERIALS AND METHODS}

Haryana is one of those states in India in which sex ratio is among the low est and illegal abortions are among the highest and a literacy rate of $81.6 \%$. The number of unsafe abortions has al so been increasing despite legal ization of abortion in India through M TP Act in $1972 .{ }^{6}$ However, morbidity associated with abortion is preventable to a great extent through use of suitable contraception. This study aims at highlighting the attitude toward contraceptive use leading to this. The study was conducted between September 2009 and October 2010 among women attending postpartum OPD at PGIMS, Rohtak. $B$ oth the patients and attenders were included in the study. A questionnaire was developed and pretested in a group of patients to test the feasibility of the study and questions were changed accordingly. No form of identification was required of the respondents. A nonymity and confidentiality of the questionnaire was ensured.

\section{Study Material}

A questionnaire was used in which demographic information regarding age, religion, education, marital status, parity and number of spontaneous as well as induced abortions was included. Basic awareness among the patients about contraceptive methods was evaluated. Information on ECP was taken in detail, like its availability, side effects, method of use and knowledge of time frame within which it should be taken. Knowledge about contraceptive methods was assessed by 
questionnaire method which included questions on awareness of contraceptive methods, type of contraceptive methods, source of knowledge and advantages and disadvantages of the method. Sources in awareness about contraceptive methods included media, friends and family members. A wareness of emergency contraception was also assessed.

Questions were also asked about the effect of emergency contraceptive pills on sexual behavior, fertility in general. The questionnaires were given directly to the patients and were asked to complete these itself before examination of the patients in the waiting area.

\section{Consent}

The purpose of the study was explained by the medical social worker and a verbal consent was obtained from the patient. A fter the interview subjects were explained about any doubts and informed about the correct methods of using e-pill and its status over the counter drug.

\section{Statistical Analysis}

In analyzing the data, we used simple proportions and percentages.

\section{Demographic Characteristics}

Total of 500 women were enrolled in the study, of which 50 (10\%) refused for interview. Finally 450 women completed the questionnaire. The mean age of women was 30 years (SD $=2.4$ years); $65.1 \%$ women were literate and $34.9 \%$ were illiterate; $66.8 \%$ (301 women) belonged to rural background and $33.2 \%$ (149 women) belonged to urban background. The adolescent population was 2\% (9 subjects); $20 \%$ (90 women) had induced abortions once and all of them were married. A bout $4.4 \%$ (20 women) underwent abortions twice or more. M ajority (93.1\%) 419 of study women were married, 31 (6.9\%) were unmarried.

\section{Awareness of Contraception Practices}

All women had knowledge about at least one contraceptive methods. M ajority (92\%) of the married women, used some form of contraception if they did not desire fertility. Natural methods used by $30 \%$ (135 women), like spacing, rhythm and withdrawal methods; reversible methods, like condoms, used by $38 \%$ (171 women), copper T $11.1 \%$ (50), were more practiced. OCP were used in $9 \%$ (40 women). $70 \%$ were regular users and $30 \%$ women were irregular users. A II the unmarried subjects were aware of some contraceptive method but none of them was sexually active. A bout 4\% (18 women) opted for permanent method of sterilization, $12.2 \%$ women knew about emergency contraception. No one was aware of injectable or implantable contraceptives. The main source of information was media, friends, health providers and internet.

\section{Awareness of Emergency Contraception}

Only $12.2 \%$ (55 women) respondents were aware of $\mathrm{EC}$ methods. A mong 55 women who were aware of $E C$, the majority 43 women $(78.1 \%)$ knew that they were in the form of pills. Five women (10\%) were aware of IUD to be used as an emergency contraceptive method, three women just knew that some treatment is available for emergency contraception but exact details were not known to them. Few (7.2\%) women believed in al ternative medicine remedies.

$M$ ajority of them were not clear of the exact time frame in which pills had to be taken. Only (16.3\%) nine women knew that a woman should take the ECP within 72 hours of unprotected sex. A round 25 (45.4\%) women thought that it was effective only if taken immediately after unprotected sex, while $18(32.7 \%)$ felt it works, if taken within 12 hours of unprotected sex, and 3 (5.4\%) were not sure about the time frame of effectiveness.

The source of awareness was media (television, radio, internet), friends, health care workers. M ost of them (80\%) thought doctor prescription is must and can be obtained only from hospitals whereas 20\% thought it is over the counter drug. Of the 55 girls who knew about ECP, 10 (18.2\%) did not know about the side effects. M ajority $(97.9 \%)$ thought that taking ECP might cause weight gain, menstrual disturbances, nausea, vomiting and hormonal changes in them. EC pills were actually used by 40 women $(72.72 \%)$ after unprotected intercourse. $M$ ajority $80.5 \%$ felt that it had no effect on fertility.

\section{DISCUSSION}

The $\mathrm{N}$ ational Family Health Survey in 1995 revealed that in India $78 \%$ of conceptions that occur annually are unplanned, and $25 \%$ of these are unwanted, thus contributing substantially to the 11 million abortions induced every year in India. Emergency contraception can provide backup, in addition to regular methods of contraception. ${ }^{10}$ The hormonal EC pills reduce the risk of pregnancy by up to $95 \%$, and EC IUD insertion reduces such risk by $99.9 \% .{ }^{11}$ The large number of induced abortions in India reflect the unmet need for contraceptive usage, and thus indirectly supports the need for emphasis on EC. ${ }^{12}$ Emergency contraception is al so required in cases of sexual assault. ${ }^{13}$

The contraceptive prevalence rate indicated in the $\mathrm{N}$ ational Family Health Survey 1998 to 1999 was $48.2 \%{ }^{14}$ whereas in our general population-based study prevalence was $92 \%$. The contraceptive methods used were spacing methods in $79.1 \%$ of women and permanent method in only $4 \%$ of women. The resul ts correlate with that of $\mathrm{K}$ anojia et al that spacing methods were more popular. ${ }^{15}$ Steroidal contraception was used by $2.6 \%$ of women, which is similar to ICM R task force study in which only $6 \%$ of women opted for oral contraceptive use. ${ }^{16}$ The Indian scenario is different from U nited States where oral pills are the most popular reversible method of contraception. ${ }^{17}$ It is evident from the present study that the participants' awareness pertaining to various methods of contraception was more as compared to their knowledge regarding $\mathrm{EC}$, which was rather insufficient $(12.2 \%)$. This was higher than that reported by Tripathi et al ${ }^{12}$ and drastically low as compared to women of developed countries. ${ }^{8,9}$ Even in educated working women in India, only $11.2 \%$ were aware of emergency contraception. ${ }^{18}$ 
In California in a 'general practice' -based population study by Glei et al of 1,290 women of reproductive age, $28 \%$ had heard of ECP. ${ }^{5}$ The awareness level about EC was reported as high as $93 \%$ in teenagers in Southeast Scotland by Grahm. ${ }^{19}$ The various $W$ estern authors have reported aw areness levels of 23 to $83 \%,{ }^{8,9,20}$ Such differences in the awareness levels may be due to cultural differences and government policies. Our study highlights that even among the women who were aware of ECP, knowledge regarding correct time, availability and side effects was inadequate (14.7\%). V arious authors in W estern countries have reported to an aw areness level of 9 to $29 \%$ about usage of ECP. ${ }^{21-23}$

In India, though EC pills are available over the counter but the general population is unaware of this, and hence is not benefited. In the present study, only $21 \%$ of women were aware of 'over the counter' status whereas the majority thought that these could be obtained only on doctors prescription and from the hospitals or health centers. Our study indicates the strong need to educate the women about emergency contraception. W ider access to hormonal emergency contraception may lead to controversies in our culture. The same arguments are used against emergency contraception that were used in the past against oral contraceptive pills and other forms of what are now accepted methods of contraception. ${ }^{24}$ The reason goes that it might increase sexual risk-taking behavior, incidents of unprotected sexual intercourse or interruption of normal contraceptive measures. ${ }^{25}$ As was seen with our study availability of hormone or emergency contraception does not influence patterns of sexual behavior, and moral arguments should not be an obstacle in allowing emergency contraception to be available. Studies from W estern countries and A sia al so support the same beli ef ${ }^{26-28}$ and rather, it was found that use of EC might be the stimulus that brings women into contact with health care providers, thus providing opportunities for counseling in matters of responsible sexual behavior, contraception and prevention of sexually transmitted diseases, including HIV /AIDS. ${ }^{7}$

The strength of our study lies in the fact that it focused on general population reflecting the unmet goals of Family W elfare Program. A nother encouraging observation of the study was that $84 \%$ of women were willing to use emergency contraception if educated about it. A 3-year program of training for health care providers and multifaceted information campaign for general public from 1997 to 2000 in M exico City showed that emergency contraception awareness increased significantly from 13 to $32 \%{ }^{29}$

\section{CONCLUSION}

EC pill is an effective tool in preventing unwanted pregnancies and thus saving women of abortions and associated morbidity. But any devel opment in health care is useless till the beneficiaries are not made aware of them. The time now demands emphasis on spreading awareness and easy accessibility about the latest methods of contraception, especially E-pill, may be through media or health professionals.

\section{REFERENCES}

1. Foster DG, Harper CC, B ley JJ, M ikanda J J, Induni M, Saviano $E C$, et al. K nowledge of emergency contraception among women aged 18 to 44 in California. A m J Obstet Gynecol 2004;191: 150-56.

2. N guyen L, Bianchi-Demicheli F, Ludicke F. Women's knowledge and opinions of emergency contraception. Int J Gynaecol Obstet 2003;82:229-30.

3. Burton R, Savage W. Knowledge and use of postcoital contraception: A survey among health professionals in Tower Hamlets. Br J Gen Pract 1990;40:326-30.

4. Delbanco S, M auldon T. L ittle knowledge and limited practice: E mergency contraceptive pills, the public and the obstetrician, Gynecologist. A m J Obst Gynaecol 1997;89:1006-11.

5. Glei DA. M easuring contraceptive use patterns among teenage and adult women. Fam Plann Perspect 1999;31:73-80.

6. Consortium of $\mathrm{N}$ ational Consensus for Emergency Contraception (2001). R eport and Recommendations, Organized by WHO-CCR in Human Reproduction, A IIM S in collaboration with WHO, M inistry of Health and Family W elfare, ICMR, p.115.

7. Puri S, Bhatia V, Swami HM, Singh A, Sehgal A, Kaur A P. $A$ wareness of emergency contraception among female college students in Chandigarh, India. Indian J Med Sci 2007 Jun; 61(6):338-46.

8. A neblom G, Larson M, Odlind V, Tyden T. Knowledge, use and attitude towards emergency contraception pills among Swedish women presenting for induced abortion. $\mathrm{Br}$ J Obstet Gynaecol 2002;109:155-60.

9. M CD onald G, A mir L. W omen's knowledge and attitudes about emergency contraception: A survey M el bourne women's health clinic. A ust NZJ Obstet Gynaecol 1999;39:460-64.

10. Emergency contraception. Training manual for health care providers. WHO collaborative centre for Research in Human Reproduction, Dept of Obs and Gynae AlIMS, New Delhi 2000:17-18.

11. Harper C, Cynthia C. Tolerability of levonorgesterol emergency contraceptions in adolescents. A m J Obstet Gynaecol 2004; 173:1158-63.

12. Tripathi $R, R$ athore $A M$, Sachdeva J. Emergency contraception: knowledge, attitude, and practices among health care providers in North India. J O bstet Gynaecol Res J un 2003;29(3):142-46.

13. Gold M A, Schein A, Coupey SM . Emergency contraception: A national survey of adolescent health experts. Fam Plann Perspect 1997;29:15-24.

14. IIPS. National Family Health Survey (NFHS-2)- India (19981999): Family Planning and Contraceptive U se, International Institute of Population Sciences, M umbai, 2000;129-144.

15. K anojia J K, N irbhavane NC, T oddywala VS, B etrabet SS, Patel SB, Datte $S$, et al. Dynamics of contraceptive practice among urban Indian women. N atl M ed J India 1996;9:109-12.

16. Baveja R, Buckshee K, Das K, Das SK, Hazra M N, Gopalan S, et al. Evaluating contraceptive choice through the method-mix approach (A n ICMR Task Force Study). Contraception 2000;61:113-19.

17. Johansson ED. Future developments in hormonal contraception. A m J Obstet Gynaecol 2004;190 (Suppl 4):S69-71.

18. Takkar N, Goel P, Saha PK, Dua D. Contraceptive practices and awareness of emergency contraception in educated w orking women. Indian J M ed Sci 2005 A pr; 59(4):143-49. 
19. Graham A, Green L, Glasier A. Teenager's knowledge of emergency contraception. Questionnaire survey in Southeast Scotland. BMJ 1996;312:1567-69.

20. B elzer $M, Y$ oshida $E$, T ejirian $T$. A dvanced supply of emergency contraception for adolescent mothers increased utilization without reducing condom or primary contraception use. J A dolesc Health 2003;32:122-23.

21. Pearson V, O wen M R, Phillips DR, Periera G, R ay DJ. Pregnant teenagers' knowledge of use of emergency contraception. BM J 1995;40:326-30.

22. Crosier A. W omen's knowledge and awareness of emergency contraception. Br J Fam Plann 1996;22:87-90.

23. Ronald A, C hez M D. Emergency oral contraception. Int J O bstet Gynaecol 2002;78:191-98.

24. Ball D. Hormonal emergency contraception: Increasing awareness and access. Indian J M ed Sci 2007;61:323-24.

25. Raine T, Harper CC, R occa CH, Fischer R, Padian N, K lausner $J D$, et al. Direct access to emergency contraception through pharmacies and effect on unintended pregnancy and STIs. J A M A 2005;293:54-62

26. Lo SS, Fan SY. Effect of advanced provision of emergency contraception on women's behavior: A randomized control trial. Hum Reprod 2004;19:2404-10.

27. Jackson RA, Bimla E. A dvance supply of emergency contraception: Effect on use and usual contraceptionrandomized control trial. Obstet Gynaecol 2003;102:8-16.
28. Glasier A, B aird D. The effects of self-administering emergency contraception. N Engl J M ed 1998;399:1-4.

29. Heimburger A, A cevedo-Garcia D, Schiavon R, L anger A, M ejia $G$, Corona $G$, et al. Emergency contraception in M edico City: $K$ nowledge, attitudes and practice providers and potential clients after a 3-year introduction effort. Contraception 2002;66: $321-29$.

\section{ABOUT THE AUTHORS}

\section{Krishna Dahiya}

Professor, Department of Obstetrics and Gynecology, Pt. BD Sharma Postgraduate Institute of M edical Sciences, R ohtak, Haryana, India

CorrespondenceAddress 74-R, M odel Town, Rohtak-124001, Haryana India, Phone: 01262211888, e-mail: krishnadahiya@ rediffmail.com drkrishnadahiya@gmail.com

\section{Sonika Mann}

Assistant Professor, Department of Obstetrics and Gynecology Pt. BD Sharma Postgraduate Institute of M edical Sciences, Rohtak Haryana, India

\section{Smiti Nanda}

Professor, Department of Obstetrics and Gynecology, Pt. BD Sharma Postgraduate Institute of M edical Sciences, R ohtak, Haryana, India 